\title{
Prevalence and risk factors associated with loss to follow-up in a cohort of HIV-infected patients treated with highly active antiretroviral treatment
} S Morreel ${ }^{1}$, T Schepens ${ }^{1}$, E Florence*2, I Kint ${ }^{2}$, O Koole ${ }^{2}$ and R Colebunders ${ }^{2}$

Address: ${ }^{1}$ Faculty of Medicine, University of Antwerp, Antwerp, Belgium and ${ }^{2}$ Institute of Tropical Medicine, Antwerp, Belgium

* Corresponding author

from Ninth International Congress on Drug Therapy in HIV Infection

Glasgow, UK. 9-13 November 2008

Published: 10 November 2008

Journal of the International AIDS Society 2008, I I (SuppI I):P228 doi:10.1 I86/I758-2652-I I-SI-P228

This abstract is available from: http://www.jiasociety.org/content/I I/SI/P228

(c) 2008 Morreel et al; licensee BioMed Central Ltd.

\section{Purpose of the study}

Most guidelines advise to organize follow-up of chronically HIV-infected patients every 3 to 4 months. However, each year patients disappear from care and are lost to follow-up (LTFU). This study describes LTFU in a population of HIV-infected patients followed at a reference outpatient clinic in Antwerp, Belgium.

\section{Methods}

Patients were considered LTFU if they did not come back for one calendar year after their last visit. Patient who received HAART were included. Patients who only came once to the consultation were excluded. The Student's unpaired t-, Mann-Whitney U- and chi-square tests were used in the statistical analysis.

\section{Summary of results}

1,302 HAART-treated patients came at least twice to the consultation in the period 2000-2006 and were included in this study. The total number of consultations throughout the study period was 29,500. A total of 289 patients $(22.2 \%)$ were out of care for at least one year during this period. Of these, 47 died (3.6\%) and 31 went to another hospital $(2.4 \%)$; the remainder $(\mathrm{n}=211 ; 16.2 \%)$ were LTFU. The average LTFU rate was $2.3 / 100$ patients/year and remained stable across the years. The LTFU patients were more often heterosexual and intravenous drug users (IVDU). Moreover, they were more often uncovered by health insurance and were living outside the province of Antwerp. They had more often detectable viral loads on their last visit, were longer in care, and had fewer followup visits on average per year. The first HAART regimen was shorter among LTFU patients. Ethnic origin, gender, baseline CD4 count, hepatitis C status, total length of treatment, and language spoken were not significantly associated with LTFU.

\section{Conclusion}

Patients without health insurance, having to travel longer distance to reach the clinic, and IVDU users are at risk for LTFU. Such patients should be the target of reinforced counseling and follow-up. The LTFU patients frequently disappeared from care with a detectable viral load with the risk of further spread of potentially resistant virus. 